\title{
On a Class of One-Switch Multiattribute Utility Functions
}

\section{J. ChudziaK*}

\author{
Department of Mathematics, University of Rzeszów, Rejtana 16C, 35-959 Rzeszów, Poland
}

\begin{abstract}
We determine the functional forms of a class of multiattribute utility functions that lead to zero-switch change in preferences between multi-period cash flows when a decision maker's initial wealth increases through an annuity that pays a constant amount every time period.
\end{abstract}

PACS: 89.65.Gh

\section{Introduction}

Several authors have presented methods to assess and derive the functional form of a single-attribute utility function based on the change in valuation of a lottery as the decision maker's wealth increases (Abbas [1], Abbas and Aczél [2], Bell [7], Pfanzagl [9]). Bell [7] introduced and developed the idea of characterizing a utility function based on the maximum number of switches that may occur between any two lotteries as the decision maker's wealth increases. In particular, if preferences between the two lotteries can change, but can change only once, as we increase $z$, then the decision maker is said to have a one-switch utility function. Abbas and Bell [4] showed that a one-switch utility function, $U$, must satisfy the system of functional equations

$$
\begin{aligned}
& U(x+z)=K(z) U(x)+M(z) W(x)+L(z), \\
& W(x+z)=k(z) W(x)+\ell(z) .
\end{aligned}
$$

In practice, a decision maker may face multi-period and uncertain cash flows. Abbas, Aczél, and Chudziak [3] and Chudziak [8] discussed the functional forms of multiattribute utility functions that lead to zero-switch change in preferences between multi-period cash flows when a decision maker's initial wealth increases through an annuity that pays a constant amount $z$ every time period. In Abbas and Chudziak [5] the functional forms of multiple attribute utility functions that lead to a maximum of one-switch change in preferences have been determined. More precisely, the solutions of the following system of functional equations:

$$
\begin{aligned}
& U\left(x_{1}+z, \ldots, x_{n}+z\right)=K(z) U\left(x_{1}, \ldots, x_{n}\right) \\
& \quad+M(z) W\left(x_{1}, \ldots, x_{n}\right)+L(z) \\
& W\left(x_{1}+z, \ldots, x_{n}+z\right)=k(z) W\left(x_{1}, \ldots, x_{n}\right)+\ell(z)
\end{aligned}
$$

for $\left(x_{1}, \ldots, x_{n}\right) \in D$ and $z \in V_{\left(x_{1}, \ldots, x_{n}\right)}$, have been determined under the assumption that $D$ is a nonempty subset of $\mathbb{R}^{n}(n \geq 2)$ such that, for every $\left(x_{1}, \ldots, x_{n}\right) \in D$, the

* e-mail: chudziak@univ.rzeszow.pl set $V_{\left(x_{1}, \ldots, x_{n}\right)}:=\left\{z \in \mathbb{R} \mid\left(x_{1}+z, \ldots, x_{n}+z\right) \in D\right\}$ is an open interval and a function

$$
V_{\left(x_{1}, \ldots, x_{n}\right)} \ni z \rightarrow W\left(x_{1}+z, \ldots, x_{n}+z\right)
$$

is nonconstant for at least one $\left(x_{1}, \ldots, x_{n}\right) \in D$.

In the present paper we determine all solutions of the system (1)-(2) under the assumption that the function given by (3) is constant for every $\left(x_{1}, \ldots, x_{n}\right) \in D$. In this way we complete the results in [5].

\section{Preliminaries}

We introduce the following notation:

$$
\begin{aligned}
V_{D} & :=\bigcup_{\left(x_{1}, \ldots, x_{n}\right) \in D} V_{\left(x_{1}, \ldots, x_{n}\right)}, \\
T & :=\left\{\left(x_{2}-x_{1}, \ldots, x_{n}-x_{1}\right) \mid\left(x_{1}, \ldots, x_{n}\right) \in D\right\} .
\end{aligned}
$$

Moreover, for every $\left(t_{1}, \ldots, t_{n-1}\right) \in T$, we put

$$
\begin{aligned}
& D_{\left(t_{1}, \ldots, t_{n-1}\right)}:=\left\{\left(x_{1}, \ldots, x_{n}\right) \in D\right. \\
& \left.\left(x_{2}-x_{1}, \ldots, x_{n}-x_{1}\right)=\left(t_{1}, \ldots, t_{n-1}\right)\right\}
\end{aligned}
$$

and

$$
V^{\left(t_{1}, \ldots, t_{n-1}\right)}:=\bigcup_{\left(x_{1}, \ldots, x_{n}\right) \in D_{\left(t_{1}, \ldots, t_{n-1}\right)}} V_{\left(x_{1}, \ldots, x_{n}\right)} .
$$

Furthermore, given a function $\psi: T \rightarrow \mathbb{R}$, we set

$$
V_{\psi \neq 0}:=\bigcup_{\left(x_{1}, \ldots, x_{n}\right) \in D_{\left(t_{1}, \ldots, t_{n-1}\right)}, \psi\left(t_{1}, \ldots, t_{n-1}\right) \neq 0} V_{\left(x_{1}, \ldots, x_{n}\right)} .
$$

Let us recall that a function $a: \mathbb{R} \rightarrow \mathbb{R}$ is said to be additive, provided it satisfies $a(x+y)=a(x)+a(y)$ for $x, y \in \mathbb{R}$; and a function $E: \mathbb{R} \rightarrow \mathbb{R}$ is said to be $e x$ ponential, provided $E(x+y)=E(x) E(y)$ for $x, y \in \mathbb{R}$. It is well known (see e.g. [6]) that every nonconstant additive or exponential function is nonconstant on every non-degenerated interval. We consider the system of functional equations (1) and (2), where $U, W: D \rightarrow \mathbb{R}$ and $K, L, M, k, \ell: V_{D} \rightarrow \mathbb{R}$ are unknown functions. The following theorem will play a crucial role in our considerations (cf. [8, Theorem 2, p. 674]).

Theorem 1. Let $D$ be a nonempty subset of $\mathbb{R}^{n}$ such that, for every $\left(x_{1}, \ldots, x_{n}\right) \in D, V_{\left(x_{1}, \ldots, x_{n}\right)}$ is an open 
interval. Assume that $W: D \rightarrow \mathbb{R}, k, \ell: V_{D} \rightarrow \mathbb{R}$ and the function given by (3) is constant for every $\left(x_{1}, \ldots, x_{n}\right) \in$ $D$. Then a triple $(W, k, \ell)$ satisfies Eq. (1) if and only if there exist a constant $d \in \mathbb{R}$ and a function $\psi: T \rightarrow \mathbb{R}$ such that

$$
\begin{aligned}
& \quad \psi\left(t_{1}, \ldots, t_{n-1}\right)=d \\
& \quad \text { whenever } V^{\left(t_{1}, \ldots, t_{n-1}\right)} \backslash k^{-1}(\{1\}) \neq \emptyset, \\
& \quad \ell(z)=d(1-k(z)) \text { for } z \in V_{D} \\
& \text { and } \\
& \quad W\left(x_{1}, \ldots, x_{n}\right)=\psi\left(x_{2}-x_{1}, \ldots, x_{n}-x_{1}\right) \\
& \text { for }\left(x_{1}, \ldots, x_{n}\right) \in D \text {. }
\end{aligned}
$$$$
\text { and }
$$

Let us also recall the following remark (cf. [8, Remark 1, p. 674]).

Remark 1. For every $\left(t_{1}, \ldots, t_{n-1}\right) \in T$, the set $V^{\left(t_{1}, \ldots, t_{n-1}\right)}$ is an open interval symmetric with respect to 0 .

\section{Main results}

Let us begin this section with the following observation.

Remark 2. Dealing with the solutions of the system (1)-(2) it is reasonable to assume that $M$ is not identically 0 . In fact, if $M$ is identically 0 , then equations (1) and (2) are independent and each of them can be easily solved by applying [8, Theorem 1, p. 673]) and Theorem 1 .

The next theorem is a main result of the paper.

Theorem 2. Let $D$ be a nonempty subset of $\mathbb{R}^{n}(n \geq$ 2) such that, for every $\left(x_{1}, \ldots, x_{n}\right) \in D, V_{\left(x_{1}, \ldots, x_{n}\right)}$ is an open interval. Assume that $U, W: D \rightarrow \mathbb{R}, K, L, M, k, \ell$ : $V_{D} \rightarrow \mathbb{R}, M$ is not identically 0 and a function given by (3) is constant for every $\left(x_{1}, \ldots, x_{n}\right) \in D$. Then the functions $U, W, K, L, M, k, l$ satisfy system (1)-(2) if and only if one of the following conditions holds:

(i) there exist an open interval (possibly empty) $I \subset V_{D}$ symmetric with respect to 0, a nonconstant exponential function $E: \mathbb{R} \rightarrow \mathbb{R}$, a function $\psi: T \rightarrow \mathbb{R}$, a not identically zero function $\phi: T \rightarrow \mathbb{R}$ and constants $b, c, d \in$ $\mathbb{R}$ such that (5) and (6) hold,

$$
\begin{aligned}
& \psi\left(t_{1}, \ldots, t_{n-1}\right)=d \\
& \quad \text { whenever } V^{\left(t_{1}, \ldots, t_{n-1}\right)} \backslash\left(k^{-1}(\{1\}) \cap I\right) \neq \emptyset, \\
& K(z)=E(z) \text { for } z \in V_{\phi \neq 0}, \\
& L(z)=c(1-K(z))-d M(z) \text { for } z \in V_{D}, \\
& M(z)=b(1-K(z)) \text { for } z \in I, \\
& U\left(x_{1}, \ldots, x_{n}\right)=E\left(x_{1}\right) \phi\left(x_{2}-x_{1}, \ldots, x_{n}-x_{1}\right) \\
& \quad+b\left(\psi\left(x_{2}-x_{1}, \ldots, x_{n}-x_{1}\right)-d\right)+c
\end{aligned}
$$

for $\left(x_{1}, \ldots, x_{n}\right) \in D$;

(ii) there exist an open interval (possibly empty) $I \subset$ $V_{D}$ symmetric with respect to 0 , a subset (possibly empty) $T_{0}$ of $T$, the functions $\phi: T_{0} \rightarrow \mathbb{R}, \psi: T \rightarrow \mathbb{R}$ and constants $b, c, d \in \mathbb{R}$ such that (5)-(7), (9) and (10) hold,

$$
\begin{aligned}
& K(z)=1 \text { for } z \in \bigcup_{\left(t_{1}, \ldots, t_{n-1}\right) \in T_{0}} V^{\left(t_{1}, \ldots, t_{n-1}\right)}, \\
& U\left(x_{1}, \ldots, x_{n}\right)=
\end{aligned}
$$

$$
\left\{\begin{array}{l}
\phi\left(x_{2}-x_{1}, \ldots, x_{n}-x_{1}\right) \\
\text { if }\left(x_{2}-x_{1}, \ldots, x_{n}-x_{1}\right) \in T_{0} \\
b\left(\psi\left(x_{2}-x_{1}, \ldots, x_{n}-x_{1}\right)-d\right)+c \\
\quad \text { if }\left(x_{2}-x_{1}, \ldots, x_{n}-x_{1}\right) \in T \backslash T_{0}
\end{array}\right.
$$

(iii) $K$ is identically 1 and there exist an open interval (possibly empty) $I \subset V_{D}$ symmetric with respect to 0 , nonconstant additive functions $A_{0}, A_{1}: \mathbb{R} \rightarrow \mathbb{R}$, the functions $\phi, \psi: T \rightarrow \mathbb{R}$ and a constant $d \in \mathbb{R}$ such that (5)-(7) hold,

$$
\begin{aligned}
& L(z)=A_{1}(z)-d M(z) \text { for } z \in V_{D}, \\
& M(z)=A_{0}(z) \text { for } z \in I, \\
& U\left(x_{1}, \ldots, x_{n}\right)= \\
& \quad A_{0}\left(x_{1}\right)\left(\psi\left(x_{2}-x_{1}, \ldots, x_{n}-x_{1}\right)-d\right)+A_{1}\left(x_{1}\right) \\
& \quad+\phi\left(x_{2}-x_{1}, \ldots, x_{n}-x_{1}\right) \\
& \text { for }\left(x_{1}, \ldots, x_{n}\right) \in D .
\end{aligned}
$$

Prof: Assume that the functions $U, W, K, L, M, k, l$ satisfy system (1)-(2). If $W$ is constant, say $W=d$ with some $d \in \mathbb{R}$, then (1) becomes

$$
\begin{aligned}
& U\left(x_{1}+z, \ldots, x_{n}+z\right)= \\
& K(z) U\left(x_{1}, \ldots, x_{n}\right)+d M(z)+L(z)
\end{aligned}
$$

for $\left(x_{1}, \ldots, x_{n}\right) \in D_{\left(t_{1}, \ldots, t_{n-1}\right)}$ and $z \in V_{\left(x_{1}, \ldots, x_{n}\right)}$. Hence, applying [8, Theorem 1, p. 673] and Theorem 1, we obtain $(i)$-(iii) with $I=\emptyset$ and $T_{0}:=\left\{\left(t_{1}, \ldots, t_{n-1}\right) \in\right.$ $\left.T \mid V^{\left(t_{1}, \ldots, t_{n-1}\right)} \subset K^{-1}(\{1\})\right\}$. Assume that $W$ is not constant. Then, according to Theorem 1 , there exist a $d \in \mathbb{R}$ and a nonconstant function $\psi: T \rightarrow \mathbb{R}$ such that (4)-(6) hold. Put

$$
I=\bigcup_{\left(t_{1}, \ldots, t_{n-1}\right) \in T \backslash T_{\psi}} V^{\left(t_{1}, \ldots, t_{n-1}\right)},
$$

where $T_{\psi}$ is a (possibly empty) subset of $T$ consisting of all elements $\left(s_{1}, \ldots, s_{n-1}\right) \in T$ such that, for every $\left(t_{1}, \ldots, t_{n-1}\right) \in T$, the following implication holds:

$$
\begin{aligned}
& V^{\left(s_{1}, \ldots, s_{n-1}\right)} \subset V^{\left(t_{1}, \ldots, t_{n-1}\right)} \\
& \quad \Rightarrow \psi\left(t_{1}, \ldots, t_{n-1}\right)=\psi\left(s_{1}, \ldots, s_{n-1}\right) .
\end{aligned}
$$

Note that as $\psi$ is nonconstant, we have

$$
T_{\psi} \neq T \text {. }
$$

Thus, by Remark 1, I given by (16) is an open interval symmetric with respect to 0 . Moreover, from the definition of $T_{\psi}$, in view of Remark 1 , it follows that $\psi$ is constant on $T_{\psi}$ and, for every $\left(t_{1}, \ldots, t_{n-1}\right) \in T$, it holds $V^{\left(t_{1}, \ldots, t_{n-1}\right)} \backslash I \neq \emptyset \Rightarrow\left(t_{1}, \ldots, t_{n-1}\right) \in T_{\psi}$. Therefore there is a $\tilde{d} \in \mathbb{R}$ such that

$$
\begin{aligned}
& \psi\left(t_{1}, \ldots, t_{n-1}\right)=\tilde{d} \\
& \quad \text { whenever } V^{\left(t_{1}, \ldots, t_{n-1}\right)} \backslash I \neq \emptyset .
\end{aligned}
$$

Thus, taking into account Remark 1, from (4) and (19) we derive (7).

Next note that from the definition of $T_{\psi}$, by Remark 1 , it follows that for every $\left(s_{1}, \ldots, s_{n-1}\right) \in T \backslash T_{\psi}$ and $\left(t_{1}, \ldots, t_{n-1}\right) \in T_{\psi}$ it holds $V^{\left(s_{1}, \ldots, s_{n-1}\right)} \subset V^{\left(t_{1}, \ldots, t_{n-1}\right)}$. Hence, in view of (16), we get 
$I \subset V^{\left(t_{1}, \ldots, t_{n-1}\right)}$ for $\left(t_{1}, \ldots, t_{n-1}\right) \in T_{\psi}$

and

$$
\bigcup_{\left(t_{1}, \ldots, t_{n-1}\right) \in T_{\psi}} V^{\left(t_{1}, \ldots, t_{n-1}\right)}=V_{D}
$$$$
\text { provided } T_{\psi} \neq \emptyset \text {. }
$$

Furthermore, by (1) and (6), we obtain that

$$
\begin{aligned}
& U\left(x_{1}+z, \ldots, x_{n}+z\right)=K(z) U\left(x_{1}, \ldots, x_{n}\right) \\
& \quad+M(z) \psi\left(t_{1}, \ldots, t_{n-1}\right)+L(z)
\end{aligned}
$$

for every $\left(t_{1}, \ldots, t_{n-1}\right) \in T,\left(x_{1}, \ldots, x_{n}\right) \in D_{\left(t_{1}, \ldots, t_{n-1}\right)}$ and $z \in V_{\left(x_{1}, \ldots, x_{n}\right)}$. Since for every $\left(t_{1}, \ldots, t_{n-1}\right) \in T$ and $\left(x_{1}, \ldots, x_{n}\right) \in D_{\left(t_{1}, \ldots, t_{n-1}\right)}$, we have

$$
\left\{z \in \mathbb{R} \mid\left(x_{1}+z, \ldots, x_{n}+z\right) \in D_{\left(t_{1}, \ldots, t_{n-1}\right)}\right\}=V_{\left(x_{1}, \ldots, x_{n}\right)},
$$

applying [8, Theorem 1, p. 673] and Theorem 1, we conclude that, for every $\left(t_{1}, \ldots, t_{n-1}\right) \in T$, one of the subsequent two possibilities holds:

(a) $K$ is identically 1 on $V^{\left(t_{1}, \ldots, t_{n-1}\right)}$ and there exists an additive function (possibly identically zero) $a_{\left(t_{1}, \ldots, t_{n-1}\right)}$ : $\mathbb{R} \rightarrow \mathbb{R}$ such that

$$
M(z) \psi\left(t_{1}, \ldots, t_{n-1}\right)+L(z)=a_{\left(t_{1}, \ldots, t_{n-1}\right)}(z)
$$

for $z \in V^{\left(t_{1}, \ldots, t_{n-1}\right)}$;

(b) $K$ is not identically 1 on $V^{\left(t_{1}, \ldots, t_{n-1}\right)}$ and there exists a constant $c_{\left(t_{1}, \ldots, t_{n-1}\right)} \in \mathbb{R}$ such that

$$
\begin{aligned}
& M(z) \psi\left(t_{1}, \ldots, t_{n-1}\right)+L(z) \\
& \quad=c_{\left(t_{1}, \ldots, t_{n-1}\right)}(1-K(z)) \text { for } z \in V^{\left(t_{1}, \ldots, t_{n-1}\right)} .
\end{aligned}
$$

Let $T_{a}$ and $T_{b}$ denote the sets of all elements of $T$ for which $(a)$ and $(b)$ is valid, respectively. Clearly, $T_{a}$ and $T_{b}$ are disjoint and $T_{a} \cup T_{b}=T$. Moreover, taking into account Remark 1, we obtain that

$$
\begin{aligned}
& \bigcup_{\left(t_{1}, \ldots, t_{n-1}\right) \in T_{b}} V^{\left(t_{1}, \ldots, t_{n-1}\right)}=V_{D} \\
& \text { provided } T_{b} \neq \emptyset .
\end{aligned}
$$

We are going to consider the following three cases:

$$
\begin{aligned}
& \text { 1. } T_{b}=T ; \\
& \text { 2. } T_{b}=\emptyset ; \\
& \text { 3. } \emptyset \neq T_{b} \neq T .
\end{aligned}
$$

Case 1. Fix $\left(t_{1}^{0}, \ldots, t_{n-1}^{0}\right) \in T \backslash T_{\psi}$ (note that by (18), the latter set is nonempty). Then there is $\left(s_{1}, \ldots, s_{n-1}\right) \in T$ such that

$$
V^{\left(t_{1}^{0}, \ldots, t_{n-1}^{0}\right)} \subset V^{\left(s_{1}, \ldots, s_{n-1}\right)}
$$

and

$$
\psi\left(t_{1}^{0}, \ldots, t_{n-1}^{0}\right) \neq \psi\left(s_{1}, \ldots, s_{n-1}\right) .
$$

Since $T_{b}=T$, making use of (23) and (25), we obtain that

$$
\begin{aligned}
& M(z) \psi\left(t_{1}^{0}, \ldots, t_{n-1}^{0}\right)-c_{\left(t_{1}^{0}, \ldots, t_{n-1}^{0}\right)}(1-K(z)) \\
& \quad=M(z) \psi\left(s_{1}, \ldots, s_{n-1}\right)-c_{\left(s_{1}, \ldots, s_{n-1}\right)}(1-K(z))
\end{aligned}
$$

for $z \in V^{\left(t_{1}^{0}, \ldots, t_{n-1}^{0}\right)}$. Hence, in view of $(26)$, we get that

$$
M(z)=b(1-K(z)) \text { for } z \in V^{\left(t_{1}^{0}, \ldots, t_{n-1}^{0}\right)},
$$
where

$$
b:=\frac{c_{\left(t_{1}^{0}, \ldots, t_{n-1}^{0}\right)}-c_{\left(s_{1}, \ldots, s_{n-1}\right)}}{\psi\left(t_{1}^{0}, \ldots, t_{n-1}^{0}\right)-\psi\left(s_{1}, \ldots, s_{n-1}\right)} .
$$

Next, taking an arbitrary $\left(t_{1}, \ldots, t_{n-1}\right) \in T \backslash T_{\psi}$ and arguing as previously, we conclude that there exists $\tilde{b} \in \mathbb{R}$ such that

$$
M(z)=\tilde{b}(1-K(z)) \text { for } z \in V^{\left(t_{1}, \ldots, t_{n-1}\right)} .
$$

However, by Remark 1 , the set $V^{\left(t_{1}^{0}, \ldots, t_{n-1}^{0}\right)} \cap V^{\left(t_{1}, \ldots, t_{n-1}\right)}$ is equal either to $V^{\left(t_{1}^{0}, \ldots, t_{n-1}^{0}\right)}$ or to $V^{\left(t_{1}, \ldots, t_{n-1}\right)}$. So, using the fact that $T_{b}=T$, from (27) and (28) we derive that $b=\tilde{b}$. Therefore, in view of (16), we obtain (10). Furthermore, taking arbitrary $\left(t_{1}, \ldots, t_{n-1}\right),\left(s_{1}, \ldots, s_{n-1}\right) \in$ $T \backslash T_{\psi}$, in view of (23) and (28), we get

$$
\begin{aligned}
& L(z)=\left(c_{\left(t_{1}, \ldots, t_{n-1}\right)}-b \psi\left(t_{1}, \ldots, t_{n-1}\right)\right)(1-K(z)) \\
& \quad=\left(c_{\left(s_{1}, \ldots, s_{n-1}\right)}-b \psi\left(s_{1}, \ldots, s_{n-1}\right)\right)(1-K(z))
\end{aligned}
$$

for $z \in V^{\left(t_{1}, \ldots, t_{n-1}\right)} \cap V^{\left(s_{1}, \ldots, s_{n-1}\right)}$. Since $T_{b}=T$, in view of Remark $1, K$ is not identically 1 on the latter set. So, (29) yields that $c_{\left(t_{1}, \ldots, t_{n-1}\right)}-b \psi\left(t_{1}, \ldots, t_{n-1}\right)=$ $c_{\left(s_{1}, \ldots, s_{n-1}\right)}-b \psi\left(s_{1}, \ldots, s_{n-1}\right)$. As $\left(t_{1}, \ldots, t_{n-1}\right)$ and $\left(s_{1}, \ldots, s_{n-1}\right)$ are arbitrary elements of $T \backslash T_{\psi}$, this means that there is a $\tilde{c} \in \mathbb{R}$ such that $c_{\left(t_{1}, \ldots, t_{n-1}\right)}-$ $b \psi\left(t_{1}, \ldots, t_{n-1}\right)=\tilde{c}$ for $\left(t_{1}, \ldots, t_{n-1}\right) \in T \backslash T_{\psi}$. Hence, by (16) and (29), we get that

$$
L(z)=\tilde{c}(1-K(z)) \text { for } z \in I .
$$

So, taking $c:=\tilde{c}+b d$ and applying (10), we obtain

$$
L(z)=c(1-K(z))-d M(z) \text { for } z \in I .
$$

Thus, if $I=V_{D}$, we get (9). If $I \neq V_{D}$, then by (16) $T_{\psi} \neq \emptyset$. Therefore, as $T_{b}=T$, in view of (7) and (23), for every $\left(t_{1}, \ldots, t_{n-1}\right) \in T_{\psi}$ and $z \in V^{\left(t_{1}, \ldots, t_{n-1}\right)}$, we have

$$
L(z)+d M(z)=c_{\left(t_{1}, \ldots, t_{n-1}\right)}(1-K(z)) .
$$

Thus, taking into account (20) and (31), we obtain that for every $\left(t_{1}, \ldots, t_{n-1}\right) \in T_{\psi}$ it holds $c_{\left(t_{1}, \ldots, t_{n-1}\right)}(1-$ $K(z))=c(1-K(z))$ for $z \in I$. Moreover, since $T_{b}=T, K$ is not identically 1 on $I$. So, the latter equality yields that $c_{\left(t_{1}, \ldots, t_{n-1}\right)}=c$ for $\left(t_{1}, \ldots, t_{n-1}\right) \in T_{\psi}$. Hence, making use of (32), we conclude that $L(z)=$ $c(1-K(z))-d M(z)$ for $z \in \bigcup_{\left(t_{1}, \ldots, t_{n-1}\right) \in T_{\psi}} V^{\left(t_{1}, \ldots, t_{n-1}\right)}$, which together with (21), gives (9). Finally, we show that

$$
\begin{aligned}
& (U-b W)\left(x_{1}+z, \ldots, x_{n}+z\right)=K(z) \\
& \quad \times(U-b W)\left(x_{1}, \ldots, x_{n}\right)+(c-b d)(1-K(z))
\end{aligned}
$$

for $\left(x_{1}, \ldots, x_{n}\right) \in D$ and $z \in V_{\left(x_{1}, \ldots, x_{n}\right)}$. To this end, fix $\left(x_{1}, \ldots, x_{n}\right) \in D$ and $z \in V_{\left(x_{1}, \ldots, x_{n}\right)}$. If $V^{\left(x_{2}-x_{1}, \ldots, x_{n}-x_{1}\right)} \subset I$, then (33) follows directly from (1), (9) and (10). If $V^{\left(x_{2}-x_{1}, \ldots, x_{n}-x_{1}\right)} \backslash I \neq \emptyset$, then by (6) and $(7)$, we get $W\left(x_{1}+z, \ldots, x_{n}+z\right)=W\left(x_{1}, \ldots, x_{n}\right)=d$. Thus, using (9), we obtain

$$
\begin{gathered}
(U-b W)\left(x_{1}+z, \ldots, x_{n}+z\right)=K(z) U\left(x_{1}, \ldots, x_{n}\right) \\
+M(z) W\left(x_{1}, \ldots, x_{n}\right)+L(z)-b W\left(x_{1}+z, \ldots, x_{n}+z\right) \\
\quad=K(z) U\left(x_{1}, \ldots, x_{n}\right)+d M(z)+L(z)-b d \\
=K(z)(U-b W)\left(x_{1}, \ldots, x_{n}\right)+(c-b d)(1-K(z)) .
\end{gathered}
$$

Therefore (33) holds. Hence, as $V^{\left(t_{1}, \ldots, t_{n-1}\right)} \backslash K^{-1}(\{1\}) \neq$ $\emptyset$ for $\left(t_{1}, \ldots, t_{n-1}\right) \in T$, applying [8, Theorem 1, p. 673] and Theorem 1 , we conclude that either

$$
(U-b W)\left(x_{1}, \ldots, x_{n}\right)=c-b d \text { for }\left(x_{1}, \ldots, x_{n}\right) \in D
$$

for $\left(x_{1}, \ldots, x_{n}\right) \in D$; or there exist a nonconstant expo- 
nential function $E: \mathbb{R} \rightarrow \mathbb{R}$ and a not identically zero function $\phi: T \rightarrow \mathbb{R}$ such that (8) is valid and

$$
\begin{aligned}
& (U-b W)\left(x_{1}, \ldots, x_{n}\right)=E\left(x_{1}\right) \phi\left(x_{2}-x_{1}, \ldots, x_{n}-x_{1}\right) \\
& \quad+c-b d \text { for }\left(x_{1}, \ldots, x_{n}\right) \in D .
\end{aligned}
$$

The first possibility, in view of (5)-(7), (9) and (10) gives (ii) with $T_{0}=\emptyset$; the second one together with (5)-(7), (9) and (10) leads to $(i)$.

Case 2. In this case $T_{a}=T$, so $K$ is identically 1. Let $\left(t_{1}^{0}, \ldots, t_{n-1}^{0}\right) \in T \backslash T_{\psi}$ and $\left(s_{1}, \ldots, s_{n-1}\right) \in T$ be such that (25) and (26) hold. Then, as $T_{a}=T$, there exist additive functions (possibly identically zero) $a_{\left(t_{1}^{0}, \ldots, t_{n-1}^{0}\right)}, a_{\left(s_{1}, \ldots, s_{n-1}\right)}: \mathbb{R} \rightarrow \mathbb{R}$ such that

$$
\begin{aligned}
& a_{\left(t_{1}^{0}, \ldots, t_{n-1}^{0}\right)}(z)-M(z) \psi\left(t_{1}^{0}, \ldots, t_{n-1}^{0}\right) \\
& \quad=a_{\left(s_{1}, \ldots, s_{n-1}\right)}(z)-M(z) \psi\left(s_{1}, \ldots, s_{n-1}\right)
\end{aligned}
$$

for $z \in V^{\left(t_{1}^{0}, \ldots, t_{n-1}^{0}\right)}$. Hence $M(z)=A_{\left(t_{1}^{0}, \ldots, t_{n-1}^{0}\right)}(z)$ for $z \in V^{\left(t_{1}^{0}, \ldots, t_{n-1}^{0}\right)}$, where $A_{\left(t_{1}^{0}, \ldots, t_{n-1}^{0}\right)}: \mathbb{R} \rightarrow \mathbb{R}$ is given by

$$
A_{\left(t_{1}^{0}, \ldots, t_{n-1}^{0}\right)}(z)=\frac{a_{\left(t_{1}^{0}, \ldots, t_{n-1}^{0}\right)}(z)-a_{\left(s_{1}, \ldots, s_{n-1}\right)}(z)}{\psi\left(t_{1}^{0}, \ldots, t_{n-1}^{0}\right)-\psi\left(s_{1}, \ldots, s_{n-1}\right)}
$$

for $z \in \mathbb{R}$. Since $a_{\left(t_{1}^{0}, \ldots, t_{n-1}^{0}\right)}$ and $a_{\left(s_{1}, \ldots, s_{n-1}\right)}$ are additive functions, so is $A_{\left(t_{1}^{0}, \ldots, t_{n-1}^{0}\right)}$. Moreover, taking an arbitrary $\left(\tilde{t}_{1}, \ldots, \tilde{t}_{n-1}\right) \in T \backslash T_{\psi}$ and using the similar arguments, we obtain that there is an additive function $A_{\left(\tilde{t}_{1}, \ldots, \tilde{t}_{n-1}\right)}: \mathbb{R} \rightarrow \mathbb{R}$ such that $M(z)=$ $A_{\left(\tilde{t}_{1}, \ldots, \tilde{t}_{n-1}\right)}(z)$ for $z \in V^{\left(\tilde{t}_{1}, \ldots, \tilde{t}_{n-1}\right)}$. Consequently, we get that $A_{\left(t_{1}^{0}, \ldots, t_{n-1}^{0}\right)}(z)=A_{\left(\tilde{t_{1}}, \ldots, t_{n-1}\right)}(z)$ for $z \in$ $V^{\left(t_{1}^{0}, \ldots, t_{n-1}^{0}\right)} \cap V^{\left(\tilde{t}_{1}, \ldots, \tilde{t}_{n-1}\right)}$. Since, by Remark 1 , the latter set is an open interval, this means that $A_{\left(t_{1}^{0}, \ldots, t_{n-1}^{0}\right)}=$ $A_{\left(\tilde{t_{1}}, \ldots, t_{n-1}\right)}$. In this way we have proved that there is an additive function $A_{0}: \mathbb{R} \rightarrow \mathbb{R}$ such that $M(z)=A_{0}(z)$ for $z \in \bigcup_{\left(t_{1}, \ldots, t_{n-1}\right) \in T \backslash T_{\psi}} V^{\left(t_{1}, \ldots, t_{n-1}\right)}$, which in view of $(16)$, gives (14). Note also that for every $\left(t_{1}, \ldots, t_{n-1}\right) \in T \backslash T_{\psi}$, a function $\Lambda_{\left(t_{1}, \ldots, t_{n-1}\right)}: \mathbb{R} \rightarrow \mathbb{R}$ given by

$$
\begin{aligned}
& \Lambda_{\left(t_{1}, \ldots, t_{n-1}\right)}(z) \\
& \quad=a_{\left(t_{1}, \ldots, t_{n-1}\right)}(z)-A_{0}(z) \psi\left(t_{1}, \ldots, t_{n-1}\right)
\end{aligned}
$$

for $z \in \mathbb{R}$, is additive and, by (14) and (22), $L(z)=$ $\Lambda_{\left(t_{1}, \ldots, t_{n-1}\right)}(z)$ for $z \in V^{\left(t_{1}, \ldots, t_{n-1}\right)}$. Since, for every $\left(t_{1}, \ldots, t_{n-1}\right) \in T \backslash T_{\psi}$, the set $V^{\left(t_{1}, \ldots, t_{n-1}\right)}$ is an open interval containing 0 , arguing as in the case of $M$ and using (16), we obtain that there is an additive function $\tilde{A}: \mathbb{R} \rightarrow \mathbb{R}$ such that

$$
L(z)=\tilde{A}(z) \text { for } z \in I .
$$

So if $I=V_{D}$, then (14) and (34) imply (13) with $A_{1}:=\tilde{A}+d A_{0}$. If $I \neq V_{D}$, then by (16) $T_{\psi} \neq \emptyset$. Thus, taking $\left(t_{1}, \ldots, t_{n-1}\right) \in T_{\psi}$ and using the fact that $T_{a}=T$, in view of (7) and (22), we get

$$
L(z)+d M(z)=a_{\left(t_{1}, \ldots, t_{n-1}\right)}(z)
$$

for $z \in V^{\left(t_{1}, \ldots, t_{n-1}\right)}$. Hence, making use of (14), (20) and (34), we obtain that

$$
\tilde{A}(z)+d A_{0}(z)=a_{\left(t_{1}, \ldots, t_{n-1}\right)}(z) \text { for } z \in I .
$$

Since $I$ is an open interval, this yields that

$$
\tilde{A}+d A_{0}=a_{\left(t_{1}, \ldots, t_{n-1}\right)} \text { for }\left(t_{1}, \ldots, t_{n-1}\right) \in T_{\psi} .
$$

Thus, by (21) and (35), we get $L(z)+d M(z)=\tilde{A}(z)+$ $d A_{0}(z)$ for $z \in V_{D}$, which again leads to (13) with $A_{1}:=\tilde{A}+d A_{0}$. Now, we claim that a function $\tilde{U}: D \rightarrow \mathbb{R}$ of the form

$$
\begin{aligned}
& \tilde{U}\left(x_{1}, \ldots, x_{n}\right) \\
& \quad:=U\left(x_{1}, \ldots, x_{n}\right)-A_{0}\left(x_{1}\right) \psi\left(x_{2}-x_{1}, \ldots, x_{n}-x_{1}\right)
\end{aligned}
$$

for $\left(x_{1}, \ldots, x_{n}\right) \in D$, satisfies equation

$$
\begin{aligned}
& \tilde{U}\left(x_{1}+z, \ldots, x_{n}+z\right) \\
& \quad=\tilde{U}\left(x_{1}, \ldots, x_{n}\right)+A_{1}(z)-d A_{0}(z)
\end{aligned}
$$

for $\left(x_{1}, \ldots, x_{n}\right) \in D$ and $z \in V_{\left(x_{1}, \ldots, x_{n}\right)}$. Let $\left(x_{1}, \ldots, x_{n}\right) \in$ $D$ and $z \in V_{\left(x_{1}, \ldots, x_{n}\right)}$. If $z \in I$, then by (1), (6), (13) and (14), we obtain

$$
\begin{aligned}
& \tilde{U}\left(x_{1}+z, \ldots, x_{n}+z\right) \\
& \quad=U\left(x_{1}+z, \ldots, x_{n}+z\right) \quad-A_{0}\left(x_{1}+z\right) \psi\left(x_{2}-x_{1}, \ldots, x_{n}-x_{1}\right) \\
&=U\left(x_{1}, \ldots, x_{n}\right)+A_{0}(z) \psi\left(x_{2}-x_{1}, \ldots, x_{n}-x_{1}\right)+A_{1}(z) \quad-d A_{0}(z)-A_{0}\left(x_{1}+z\right) \psi\left(x_{2}-x_{1}, \ldots, x_{n}-x_{1}\right) \\
& \quad=U\left(x_{1}, \ldots, x_{n}\right)-A_{0}\left(x_{1}\right) \psi\left(x_{2}-x_{1}, \ldots, x_{n}-x_{1}\right) \\
& \quad+A_{1}(z)-d A_{0}(z)=\tilde{U}\left(x_{1}, \ldots, x_{n}\right)+A_{1}(z)-d A_{0}(z) .
\end{aligned}
$$

If $z \notin I$, then $V^{\left(x_{2}-x_{1}, \ldots, x_{n}-x_{1}\right)} \backslash I \neq \emptyset$, so by $(7)$, $\psi\left(x_{2}-x_{1}, \ldots, x_{n}-x_{1}\right)=d$. Hence, in view of (1), (6) and (13), we get

$$
\begin{aligned}
\tilde{U} & \left(x_{1}+z, \ldots, x_{n}+z\right) \\
& =U\left(x_{1}+z, \ldots, x_{n}+z\right)-d A_{0}\left(x_{1}+z\right) \\
& =U\left(x_{1}, \ldots, x_{n}\right)+d M(z)+L(z)-d A_{0}\left(x_{1}+z\right) \\
& =U\left(x_{1}, \ldots, x_{n}\right)+A_{1}(z)-d A_{0}\left(x_{1}+z\right) \\
& =U\left(x_{1}, \ldots, x_{n}\right)-d A_{0}\left(x_{1}\right)+A_{1}(z)-d A_{0}(z) \\
& =\tilde{U}\left(x_{1}, \ldots, x_{n}\right)+A_{1}(z)-d A_{0}(z) .
\end{aligned}
$$

Therefore $\tilde{U}$ satisfies (37), so applying [8, Theorem 1, p. 673] and Theorem 1, we conclude that there exists a function $\phi: T \rightarrow \mathbb{R}$ such that

$$
\begin{aligned}
& \tilde{U}\left(x_{1}, \ldots, x_{n}\right) \\
& \quad=A_{1}\left(x_{1}\right)-d A_{0}\left(x_{1}\right)+\phi\left(x_{2}-x_{1}, \ldots, x_{n}-x_{1}\right)
\end{aligned}
$$

for $\left(x_{1}, \ldots, x_{n}\right) \in D$. Hence, taking into account (36), we obtain (15) and so (iii) is valid.

Case 3. Let $T_{0}:=T_{a}$. Then (12) is obvious. Furthermore, let

$$
D_{0}:=\left\{\left(x_{1}, \ldots, x_{n}\right) \in D \mid\left(x_{2}-x_{1}, \ldots, x_{n}-x_{1}\right) \in T_{b}\right\} .
$$

Then, for every $\left(x_{1}, \ldots, x_{n}\right) \in D_{0}, K$ is not identically 1 on $V^{\left(x_{2}-x_{1}, \ldots, x_{n}-x_{1}\right)}$. On the other hand, as $T_{b} \neq T$, we get $T_{a} \neq \emptyset$, whence $K$ is identically 1 on some open neighborhood of 0 . Since, by (24),

$\bigcup_{\left(x_{1}, \ldots, x_{n}\right) \in D_{0}} V_{\left(x_{1}, \ldots, x_{n}\right)}=\bigcup_{\left(t_{1}, \ldots, t_{n-1}\right) \in T_{b}} V^{\left(t_{1}, \ldots, t_{n-1}\right)}=V_{D}$, arguing as in the Case 1 (with $D$ replaced by $D_{0}$ ) we obtain that there exist an open interval $I$ symmetric with 
respect to 0 and constants $b, c, d \in \mathbb{R}$ such that (5)-(7), (9) and (10) hold, and

$$
\begin{aligned}
& U\left(x_{1}, \ldots, x_{n}\right) \\
& \quad=b\left(\psi\left(x_{2}-x_{1}, \ldots, x_{n}-x_{1}\right)-d\right)+c
\end{aligned}
$$

for $\left(x_{1}, \ldots, x_{n}\right) \in D_{0}$, that is whenever $\left(x_{2}-x_{1}, \ldots, x_{n}-\right.$ $\left.x_{1}\right) \in T_{b}=T \backslash T_{0}$. Now, we show that, for every $\left(x_{1}, \ldots, x_{n}\right) \in D \backslash D_{0}$ and $z \in V_{\left(x_{1}, \ldots, x_{n}\right)}$, it holds

$$
U\left(x_{1}+z, \ldots, x_{n}+z\right)=U\left(x_{1}, \ldots, x_{n}\right) .
$$

Fix $\left(x_{1}, \ldots, x_{n}\right) \in D \backslash D_{0}$ and $z \in V_{\left(x_{1}, \ldots, x_{n}\right)}$. Then $\left(x_{2}-x_{1}, \ldots, x_{n}-x_{1}\right) \in T_{0}$, so by $(12), K(z)=1$. Therefore, if $z \in I$ then (39) follows directly from (1), (9) and (10). If $z \notin I$, then by $(7), \psi\left(x_{2}-x_{1}, \ldots, x_{n}-x_{1}\right)=d$, so making use of (1) and (9), we get

$$
\begin{aligned}
& U\left(x_{1}+z, \ldots, x_{n}+z\right) \\
& \quad=U\left(x_{1}, \ldots, x_{n}\right)+d M(z)+L(z)=U\left(x_{1}, \ldots, x_{n}\right) .
\end{aligned}
$$

Thus, (39) is proved. So, for every $\left(x_{1}, \ldots, x_{n}\right) \in D \backslash D_{0}$, a function

$$
V_{\left(x_{1}, \ldots, x_{n}\right)} \ni z \rightarrow U\left(x_{1}+z, \ldots, x_{n}+z\right)
$$

is constant. Moreover, we have

$$
\left\{z \in \mathbb{R} \mid\left(x_{1}+z, \ldots, x_{n}+z\right) \in D \backslash D_{0}\right\}=V_{\left(x_{1}, \ldots, x_{n}\right)}
$$

for $\left(x_{1}, \ldots, x_{n}\right) \in D \backslash D_{0}$ and

$$
\left\{\left(x_{2}-x_{1}, \ldots, x_{n}-x_{1}\right) \mid\left(x_{1}, \ldots, x_{n}\right) \in D \backslash D_{0}\right\}=T_{0} .
$$

Therefore, applying Theorem 1, we obtain that there is a function $\phi: T_{0} \rightarrow \mathbb{R}$ such that $U\left(x_{1}, \ldots, x_{n}\right)=$ $\phi\left(x_{2}-x_{1}, \ldots, x_{n}-x_{1}\right)$ whenever $\left(x_{2}-x_{1}, \ldots, x_{n}-x_{1}\right) \in T_{0}$. Consequently, taking into account (38), we get ( $i i)$.

A straightforward calculation shows that if one of the conditions $(i)-($ iii $)$ holds, then the functions $U, W, K, L, M, k, l$ satisfy system (1)-(2). This completes the proof.

\section{Conclusion}

In Abbas and Chudziak [5] the concept of one-switch change in preferences between uncertain lotteries, introduced by Bell [7], has been extended to the situations involving multiple time periods, where the initial wealth increases in the form of a constant annuity payment. In particular, in [5] the corresponding functional forms of the utility functions have been determined by solving the system of functional equations (1)-(2) under the assumption that the function given by (3) is nonconstant for at least one $\left(x_{1}, \ldots, x_{n}\right) \in D$. In the present paper we complete the results in [5], that is we solve the system under the assumption that the function given by (3) is constant for every $\left(x_{1}, \ldots, x_{n}\right) \in D$. Our approach even makes possible for practical applications of them.

\section{References}

[1] A.E. Abbas, Decision Analysis 4, 17 (2007).

[2] A.E. Abbas, J. Aczél, Decision Analysis 7, 215 (2010).

[3] A.E. Abbas, J. Aczél, J. Chudziak, Result. Math. 54, 1 (2009).

[4] A.E. Abbas, D. Bell, Oper. Res. 59, 764 (2011).

[5] A.E. Abbas, J. Chudziak, Submitted.

[6] J. Aczél, J. Dhombres, Functional equations in several variables, Encyclopedia of Mathematics and its Applications 31, Cambridge University Press, 1989.

[7] D. Bell, Management Sci. 34, 1416 (1988).

[8] J. Chudziak, Acta Phys. Polon. A 117, 673 (2010).

[9] J. Pfanzagl, Naval Research Logistic Quarterly 6, 283 (1959). 